\title{
Influence of the North Atlantic oscillation on the atmospheric levels of benzo[a]pyrene over Europe
}

\author{
Pedro Jiménez-Guerrero ${ }^{1,2}$ (D) Nuno Ratola ${ }^{3}$ \\ Received: 30 November 2020 / Accepted: 8 April 2021 / Published online: 16 April 2021 \\ (c) The Author(s) 2021
}

\begin{abstract}
The atmospheric concentration of persistent organic pollutants (and of polycyclic aromatic hydrocarbons, PAHs, in particular) is closely related to climate change and climatic fluctuations, which are likely to influence contaminant's transport pathways and transfer processes. Predicting how climate variability alters PAHs concentrations in the atmosphere still poses an exceptional challenge. In this sense, the main objective of this contribution is to assess the relationship between the North Atlantic Oscillation (NAO) index and the mean concentration of benzo[a]pyrene (BaP, the most studied PAH congener) in a domain covering Europe, with an emphasis on the effect of regional-scale processes. A numerical simulation for a present climate period of 30 years was performed using a regional chemistry transport model with a $25 \mathrm{~km}$ spatial resolution (horizontal), higher than those commonly applied. The results show an important seasonal behaviour, with a remarkable spatial pattern of difference between the north and the south of the domain. In winter, higher $\mathrm{BaP}$ ground levels are found during the NAO+ phase for the Mediterranean basin, while the spatial pattern of this feature (higher BaP levels during NAO+ phases) moves northwards in summer. These results show deviations up to and sometimes over $100 \%$ in the BaP mean concentrations, but statistically significant signals $(\mathrm{p}<0.1)$ of lower changes $(20-40 \%$ variations in the signal) are found for the north of the domain in winter and for the south in summer.
\end{abstract}

Keywords North Atlantic oscillation $\cdot$ Benzo[a]pyrene $\cdot$ Chemistry/climate modelling $\cdot$ Chemical transport

\section{Introduction}

The North Atlantic Oscillation (NAO) is the normalised sea level pressure difference between the Azorean high and the Icelandic low, which is responsible for a considerable share of variability in European climate. Surface air temperature, the precipitation and evaporation balances in the Atlantic

Pedro Jiménez-Guerrero

pedro.jimenezguerrero@um.es

Nuno Ratola

nrneto@fe.up.pt

1 Physics of the Earth, Department of Physics, Regional Campus of International Excellence (CEIR) "Campus Mare Nostrum”, University of Murcia, 30100 Murcia, Spain

2 Biomedical Research Institute of Murcia (IMIB-Arrixaca), 30120 Murcia, Spain

3 LEPABE-Laboratory for Process Engineering, Environment, Biotechnology and Energy, Faculty of Engineering, University of Porto, Rua Dr. Roberto Frias, 4200-465 Porto, Portugal
Ocean and the surrounding land masses are influenced asymmetrically both in time and space (Stenseth et al. 2002).

The impacts of the NAO include a meridional sea level pressure gradient in the North Atlantic, with positive phases characterised by an intense north-south gradient and negative phases when the gradient decreases (Hurrell 1995). The strength of each NAO phase is given by the NAO index, which can be a positive or negative number, according to the phase. Its fluctuations induce considerable variations in the mean direction and speed of the wind patterns over the Atlantic (Trigo et al. 2002; Hurrell et al. 2003), the heat and moisture transport to the neighbouring continents (Dayan 2011; Christoudias et al. 2012), and the intensity and amount of storms (Trigo 2006). Consequently, given NAO's hemispheric character (Greatbatch 2000), other associated phenomena have been reported as suffering from its influence. For instance, the influxes of dust from the Sahara desert towards the Atlantic and Mediterranean (Moulin et al. 1997), and photochemical processes that have an effect on the transport of atmospheric contaminants from North America to Europe (Li et al. 2002). Ultimately, all these impacts can 
result in direct human health-related parameters, such as hospital admissions due to diseases linked to air pollution episodes (Almendra et al. 2017). Such effects are likely to influence the composition of the atmosphere, either via local processes or through a significant transport of air pollutants (Izquierdo et al. 2014; Camarero et al. 2017).

The atmospheric concentration of persistent organic pollutants (POPs), and of polycyclic aromatic hydrocarbons (PAHs) in particular, is closely related to climate change and climatic fluctuations, which are likely to influence contaminant transport pathways and transfer processes. Predicting how climate variability alters PAHs concentrations in the atmosphere still poses an exceptional challenge (Wang et al. 2010), since the existing literature on the climatological framework (long-term modelling) of the influence of NAO or other climate indexes is scarce (Eckhardt et al. 2003; Christoudias et al. 2012; Bacer et al. 2016), and practically non-existent with the aim of assessing local and large-scale approaches separately.

Regarding semi-volatile organic contaminants (SVOCs), the references to the influence of NAO on their levels and distribution in the atmosphere are scarce, and mainly focusing on polychlorinated biphenyls (PCBs) and organochlorine pesticides (OCPs). Ma et al. (2004a, b) studied the influence of NAO fluctuation on the distribution and deposition of some PCBs and OCPs in the Great Lakes region and the whole of North America, respectively, while Hung et al. (2005) did a similar work while assessing the temporal and spatial trends of the same pollutant families in the Arctic region. MacLeod et al. (2005) reported variations in the atmospheric levels of PCBs in the Northern Hemisphere due to the NAO, using a global-scale model (BETR-Global) and later Wang et al. (2010) investigated ice core concentration records of OCPs DDT and $\mathrm{HCH}$ to assess the effect of climate parameters (including NAO) on their presence in mountain glaciers. Finally, Octaviani et al. (2015) studied the meridional transport of persistent organic pollutants and their correlations with the NAO and Arctic Oscillation (AO) indicating that the net burden of PCB153 reaching the Arctic will increase under a future climate scenario. To our knowledge, there are no studies with reference to PAHs, a family of SVOCs of extreme importance and concern (ATSDR 1995).

PAHs are generated by the incomplete combustion or burning of organic carbon-containing matter, and can be found in cigarette smoke, traffic exhaust, natural fuels and as by-products of many industrial processes and natural phenomena like forest fires or volcanoes (Ravindra et al. 2008). They are ubiquitous in the environment in gas and particulate form and can have an effect on human health through several forms of exposure (inhalation, diet, etc.). Among them, benzo(a)pyrene (BaP), with a five-aromatic ring molecular structure (thus present in the atmosphere mainly as particulate matter) (Ratola and Jiménez-Guerrero 2015 ) is possibly the most studied congener of this group of compounds and is often considered as the PAHs "representative" in environmental research (Nisbet and LaGoy 1992; Ratola and Jiménez-Guerrero 2017).

PAHs have been present in our planet since the beginning and will remain as long as a fossil fuel exists, and a combustion is made. This means that they will always play a crucial role in the assessment, control and mitigation of air pollution (Dat and Chang 2017). Europe is particularly affected by PAHs, given the level of industrialization and use of fossil resources. In fact, the 2019 Air Quality Report of the European Environment Agency (EEA 2019) states that an estimated 17\% of the EU-28 urban population was exposed to annual mean $\mathrm{BaP}$ concentrations above the target value of $1 \mathrm{ng} \mathrm{m}^{-3}$ for the total content of BaP in the PM10 fraction (EU 2004). Although being the lowest value since 2008, Guerreiro et al. (2016) stated from a comprehensive modeling study over Europe that $\mathrm{BaP}$ needs to be continuously monitored as a proxy for all PAHs and the corresponding health effects estimated. And obviously, the transboundary character of airborne pollutants is a challenge for nationalbased policies. For instance, Schreiberová et al. (2020) estimated $46 \%$ and $70 \%$ of foreign contribution in the presence of $\mathrm{BaP}$ for most of the Czech Republic. A pan-European action is advisable under this scenario, since the progress in air quality mitigation is uneven within Europe. Viana et al. (2020) reported the management strategies put forward by 10 European cities (Antwerp, Berlin, Dublin, Madrid, Malmö, Milan, Paris, Plovdiv, Prague, Vienna) from 2013 to 2018 and identified several knowledge gaps that pointed towards a systemic thinking approach to the future of air quality management.

Climate change also plays a very important part in this equation since the increased frequency and intensity of extreme events complicates the establishment of monitoring strategies and mitigation measures. As an example, forest fires have been growing in number and intensity in recent years, but not only in the southern part of the domain (where they were already frequent), also in the north of Europe as in the recent wildfire events in Scandinavian countries in 2018 (Turco et al. 2019). This means that a tight control of BaP (and the rest of PAHs) is needed to face their atmospheric presence adequately. Consequently, indexes like NAO can inform about real-time changes in $\mathrm{BaP}$ concentrations in Europe and, with the help of CTMs, project the near future and long-term incidence. These data will definitely help air quality managers and legislators to decrease the environmental fingerprint of PAHs

Consequently, the objective of the current study is to assess the influence of the NAO fingerprint on the mean concentration of $\mathrm{BaP}$ in a European domain and focusing on the effect of regional-scale processes. The target domain 
comprises the whole Mediterranean basin and its areas of influence, since this is considered one of the most vulnerable areas to air pollution and climate change worldwide (Linares et al. 2020). Moreover, in recent years the influence of climate variations in air pollution over the target area has become evident (e.g. Dayan et al. (2017)), especially the influence of NAO phase in central and southern Europe and the Mediterranean basin (Christoudias et al. 2012).

\section{Materials and methods}

Taking advantage of the formulations previously reported in literature on the impact of the NAO on European aerosol ground levels (e.g. (Jerez et al. 2013b)), this approach follows an analogous methodology, applied to the widespread contaminant BaP. The novelty of this work is a contribution to the understanding of the regional processes controlled by $\mathrm{NAO}$ that affect $\mathrm{BaP}$ levels in a climatological timescale (30 years), which to our knowledge is still not established. The analysis was focused on winter and summer seasons using composites that highlight the changes in the mean fields of modelled BaP concentrations between NAO's high and low phases (NAO+ and NAO-, respectively) (Fig. 1). This figures indicates a slight trend of the NAO index observed for the summer but not any evident trend for winter, which is the main season of interest in NAO-related studies.

In brief, the NAO indexes available at the Climate Prediction Center (CPC) from the National Ocean and Atmospheric Administration (NOAA) for winter and summer months (December, January, February-DJF and June, July, August—JJA, respectively) are employed to identify positive and negative NAO stages throughout the period of study (1971-2000). The CPC/NOAA NAO index was selected in this case since it is readily available (Pey et al. 2013). Following a common approach (e.g. (Trigo et al. 2002; Jerez et al. 2013a, b)), we defined classes of NAO positive and negative phases using the detrended monthly series of the NAO index. In fact, detrending the original NAO series shown in Fig. 1 in the computational code ensures that both classes have a similar occurrence and neither NAO+ nor NAO- phase prevail at the beginning or the end of the period.

It should be noticed that different data sources and/or methods to compute the NAO index may provide different values. In particular, we are aware that the CPC/NOAA NAO index is not based on the ERA-20C data (Poli et al. 2016) used to drive WRF in our modelling system. However, at the timescale addressed here, this influence is negligible (Kumar et al. 2016; Comas-Bru and Hernández 2018). Hence, this choice is based on its easy access and up-to-date computation approach, which in fact makes it widely used nowadays in studies focused on the recent past (Bladé et al.

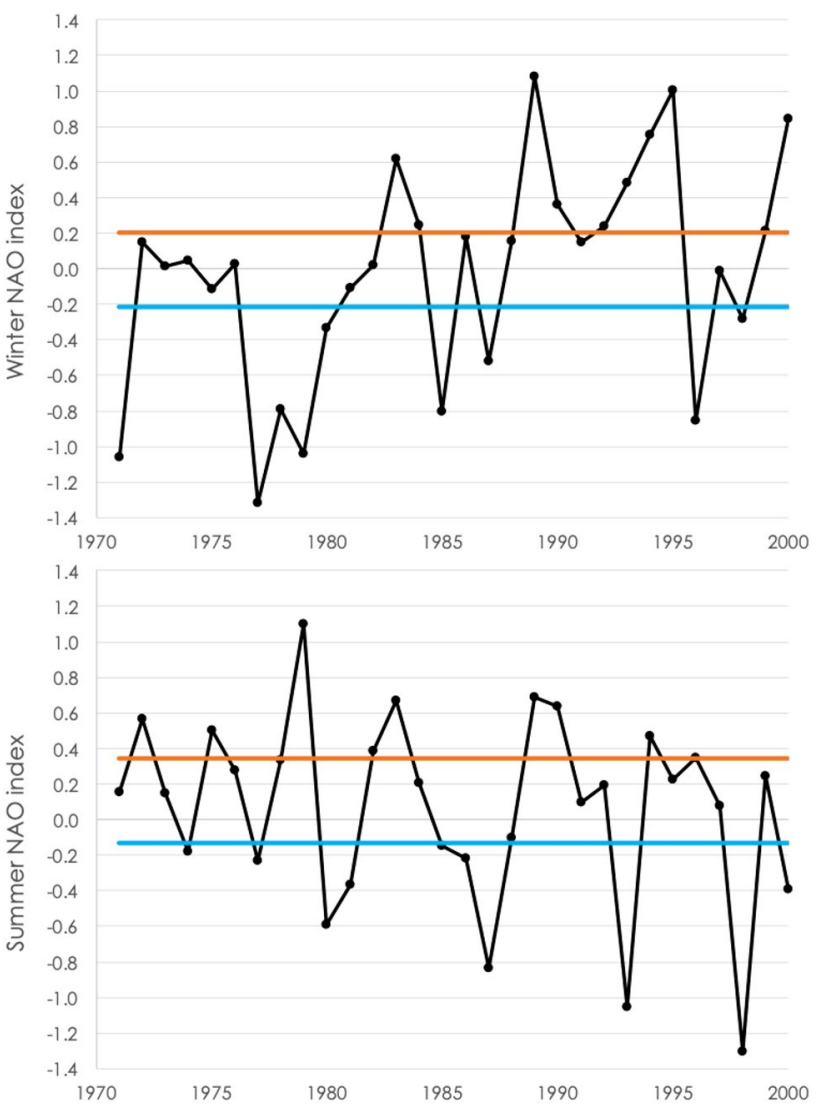

Fig. 1 Winter (top) and summer (bottom) original CPC/NOAA NAO index series for the period 1971-2000. The former are DecemberJanuary-February averages and the latter are June-July-August averages. The red (blue) lines denotes the 70th (30th) percentile value of each series. The years/values with a NAO index above (below) that percentile are selected as $\mathrm{NAO}+(\mathrm{NAO}-)$ events for the composites analysis

2012; Pey et al. 2013; Grams et al. 2017; Alizadeh-Choobari and Adibi 2019).

$\mathrm{NAO}+$ and NAO- phases are defined according to the 70th and 30th percentiles of the NAO series, respectively (Jerez et al. 2013a). The influence of the NAO on BaP concentrations is then evaluated through composites estimating the differences in the mean concentrations of $\mathrm{BaP}$ simulated for the periods with negative and positive NAO phases. The significance checks performed on the difference between $\mathrm{BaP}$ levels during NAO+ and NAO- phases follow those of Jerez et al. (2013a), and can be summarised in two requirements: if they have statistical significance above the $90 \%$ confidence level and if they are backed by temporal correlations between the NAO and the corresponding $\mathrm{BaP}$ series that are statistically significant also above the $90 \%$ confidence level. Statistical significance is evaluated by performing two-tailed t-tests for the null hypothesis of equal means or zero correlation, respectively (Snedecor and Cochran 1989). Moreover, the signal-to-noise (S/N) 
ratio (defined as the ratio between the absolute value of the $\mathrm{NAO}+$ minus $\mathrm{NAO}-$ differences in $\mathrm{BaP}$ concentrations and the standard deviation of the whole $\mathrm{BaP}$ seasonal series) is considered a relative measure of the importance of the NAOimpact. In fact, areas where the $\mathrm{S} / \mathrm{N}$ ratio is below the unit were blurred. In the other areas, the NAO-impact exceeds one standard deviation of the series and hence we are likely moving from one tail to the other of the probability density function describing the variability in the BaP levels when the NAO phase changes.

\subsection{Models and domains}

BaP levels are obtained from a simulation of the chemical composition of the atmosphere from 1971 to 2000, in a domain comprising most of Europe (Mediterranean basin and central Europe). The modelling system is WRF+CHIMERE, coupled with the European Monitoring and Evaluation Program (EMEP) emissions, and run with a horizontal spatial resolution of $25 \mathrm{~km}$. Thirty-three vertical levels are spaced unevenly up to $10 \mathrm{hPa}$, with higher resolution near the ground in order to characterize the particularities (12 model layers within the lowest $\sim 2000 \mathrm{~m}$ and 15 layers up to $\sim 5500 \mathrm{~m}$ ). This time period and resolution are significant compared to those commonly applied in climate runs for air pollution purposes. Further description can be found in the Supplemental Material and in Table SM1.

The simulation was designed to disregard the signals from the NAO impact on the long-range atmospheric transport (LRAT) by using constant climatological boundary conditions for the $\mathrm{BaP}$ concentrations. Therefore, the contribution of LRAT to changes in BaP during different NAO phases can be considered negligible, and the influence of climatological boundary conditions limited and overwhelmed by local processes.

Although the LRAT of pollutants is recognized and has been studied for some decades, its mechanisms are intricate and, for chemicals like PAHs, are far from being fully understood (Lammel et al. 2015). For BaP, the degradation and fate processes are the most uncertain (Shrivastava et al. 2017). Being almost completely associated with particulate matter, the distribution and LRAT of BaP are mainly ruled by degradation processes, particularly with ozone (Keyte et al. 2013). But also here the assessment of reaction rates and half-lives is difficult, as they are dependent on other parameters like temperature (Mu et al. 2018). Nevertheless, laboratory measurements indicate that ozone degrades particulate BaP rapidly (Zhou et al. 2019). Moreover, Lammel et al. (2009) indicated a modelled value of $48 \mathrm{~h}$ for $\mathrm{BaP}$ atmospheric lifetime, but some correction in the parameterizations in the meantime pointed towards a value of 6 h (Friedman and Selin 2012). For all these reasons, it is extremely difficult to quantify the percentage of the PAH burden attributable to LRAT but, unless in remote areas, this contribution tends to be very small compared with the local emissions (Callén et al. 2008; Lhotka et al. 2019), especially in highly populated and industrialized areas, that generally characterize our domain. Therefore, for the purposes of this study LRAT can be considered a negligible parameter.

Constant anthropogenic emissions are considered throughout the simulation period to isolate the possible impact of the NAO on the ground levels of atmospheric contamination. Further information on emissions can be found in the Suplemental Material (Fig. SM1). Moreover, the influence of climatology on airborne hazardous chemicals is estimated neglecting potential changes on anthropogenic pollutant emissions, land use, vegetation, or any feedbacks from those substances to meteorology parameters, although allowing variations regarding natural emissions (e.g. Meleux et al. (2007); Jiménez-Guerrero et al. (2012)). The NAO effects on LRAT of the target contaminant were not taken into consideration. Such settings enhance our knowledge on the role of the NAO-ruled underlying mechanisms on a regional level.

The robustness of this simulation was evaluated in other works, which rely on the same data and include the assessment of the integrations (Ratola and Jiménez-Guerrero 2015, 2016), and hence, only a short description is shown here. In brief, the validation of the modelling system used was based on the climatologies of $\mathrm{BaP}$ available in the target period, obtained from daily means coming from 13 stations belonging to the EMEP air sampling network (set at least $10 \mathrm{~km}$ off large emission sources, this data is assumed to represent regional background levels) (Tørseth et al. 2012). Ratola and Jiménez-Guerrero (2015) found that the modelling system provided consistently mean fractional biases (MFB) and mean fractional errors (MFE) in the range of 20-30\% and 30-60\%, respectively, when evaluated against EMEP stations in Europe. Moreover, the same authors reported in a subsequent study that the MFB of this modelling system varies from - 19\% for spring (March-April-May) to a minor overestimation during winter (December-January-February, $+9 \%$ ), with biases showing a slight annual underestimation around -3 picograms per cubic meter $\left(\mathrm{pg} \mathrm{m}^{-3}\right)$ (Ratola and Jiménez-Guerrero 2016). These results support the use of the modelling system as a good depiction of $\mathrm{BaP}$ air concentrations and as a valid tool to calculate their changes under different NAO phases.

\section{Results}

\subsection{NAO impact on atmospheric conditions}

This Section does not intend to provide novel insights, but essentially to evaluate the ability of our WRF simulations 
(driving the CHIMERE run) to simulate the extensively reported NAO impact on the European atmospheric conditions. As this analysis was widely conducted by Jerez et al. (2013a), we mainly summarize this work to give the reader an appropriate context for the interpretation of the $\mathrm{NAO}$ impact on $\mathrm{BaP}$ concentrations, since the analysis is specifically focused on those variables driving air pollution levels. Fig. 2 further confirms the expected NAO impact on the wind field, showing asymmetric responses in winter and summer.

In winter, $\mathrm{NAO}+(\mathrm{NAO}-)$ promotes a westerly flow in northern (southern) Europe, with the largest significant differences in the wind speed (above 10\%) appearing northward in the western sector of the domain. Conversely, in summer, $\mathrm{NAO}-$ phases are associated with a stronger westerly flow in northern Europe than in NAO+ phases, with differences in the wind module exceeding $5 \%$ and extending more eastward than in winter. Windier conditions associated to the NAO- phase prevail also in the southwest of the domain during summer, mainly around the Iberian Peninsula (differences about $5 \%$ ).

Consequences in precipitation, cloudiness and temperature derived from the former conditions are also provided in Fig. 2, as these variables play a key role on the BaP levels. $\mathrm{NAO}+$ minus $\mathrm{NAO}-$ differences in precipitation are larger in winter than in summer, when they are overall negative and affect mainly southern Europe ranging west to east from $40 \%$ $\left(50 \mathrm{~mm} \mathrm{month}^{-1}\right)$ to $20 \%\left(20 \mathrm{~mm} \mathrm{~mm} \mathrm{month}{ }^{-1}\right)$. In summer, these differences reach $20 \%$ (up to $30 \mathrm{~mm} \mathrm{~mm} \mathrm{month}^{-1}$ ) over large sectors of Europe, being negative in the north and positive (and less important) in the south. Consistently, the column integrated cloud water (a variable representative of cloudiness) shows negative values in southern Europe during winter (resembling the west to east gradient of the precipitation signal, with differences ranging from 30 to 10\%) and in northern areas during summer (differences around 10\%), and positive values in north-western areas during winter (i.e., $\mathrm{NAO}+$ enhances cloudiness there by about $20 \%$ ). Regarding the NAO impact on mean $2 \mathrm{~m}$ temperature, the most important signal consists of positive NAO+ minus NAO- differences (up to $3 \mathrm{~K}$ ) largely spread over northern Europe in winter. Smaller negative (positive) differences (up just to 1 $\mathrm{K}$ ) appear also over some southernmost (northern) areas in winter (summer).

These results support the capacity of the climate simulation to reproduce the expected responses to the NAO phase, providing a meaningful representation of how the atmospheric conditions vary between $\mathrm{NAO}+$ and $\mathrm{NAO}-$ events, that will be used to understand the NAO impact on $\mathrm{BaP}$ levels in the next Section.

\subsection{NAO impact on BaP levels}

The difference between Icelandic Low and the Azores High pressures is intensified throughout the NAO+ phases, originating a stronger separation of the flow over Europe. Under these conditions, a higher northward transport over northern latitudes and an enhanced southbound transport over the south are seen. Also, in winter, NAO+ promotes a windy west flow in north Europe whereas NAO- has a similar effect in the south. NAO+ blocks the zonal circulation in the Mediterranean basin, reducing precipitation and cloudiness there (e.g. (Trigo 2006; Jerez et al. 2013a), among others). High NAO index winters (NAO+) lead to drier weather over the Mediterranean, the majority of central and southern Europe and some areas of the east, while a precipitation rate above average falls over northern Europe (Hurrell 1995). In consequence, higher ground-level concentrations of $\mathrm{BaP}$ (almost exclusively in particulate form in air (Bidleman 1988)) are more frequently modelled during $\mathrm{NAO}+$ than during NAO- (Figs. 3 and 4), since the cleaning effect of both enhanced winds and wet deposition and the inhibitory effect of diminished solar radiation are reduced. In this sense, the 10- $\mathrm{m}$ wind speed in winter is enhanced in the $\mathrm{NAO}+$ phase by over $10 \%$ when compared to NAO- phase in the northern part of the domain.

The regions holding the highest modelled increases in $\mathrm{BaP}$ concentrations during $\mathrm{NAO}+$ and $\mathrm{NAO}-$ phases (Fig. 4) are predominantly located in the Mediterranean basin during winter (changes around 0.05 to $0.10 \mathrm{ng} \mathrm{m}^{-3}$ between NAO+ and NAO- phases). For instance, the absolute concentrations in Lisbon and in the Po Valley in northern Italy exceed $0.70 \mathrm{ng} \mathrm{m}^{-3}$ in winter (Fig. 3) during $\mathrm{NAO}+$ phases, being $0.20 \mathrm{ng} \mathrm{m}^{-3}$ higher than during NAO- in January (Fig. 4). This increase in concentration in $\mathrm{BaP}$ during $\mathrm{NAO}+$ phase is particularly evident over the Iberian Peninsula, northern Italy and Greece, where the NAO+ minus NAO- signal is clearly negative for $10-\mathrm{m}$ wind speed, precipitation and cloud water content. Thus, NAO+ raises over $100 \%$ the concentrations of $\mathrm{BaP}$ in southern Europe (Fig. 5) (especially in December, where the changes become more evident) as a consequence of the drier weather and increased stagnation associated to the $\mathrm{NAO}+$ phase over the Mediterranean area.

Conversely, in the north of France and Germany, BaP absolute background concentrations are about $0.15 \mathrm{ng} \mathrm{m}^{-3}$ during NAO+ positive phase (Fig. 3), and reductions up to $-0.10 \mathrm{ng} \mathrm{m}^{-3}$ (Fig. 4) are associated to NAO+ phases vs. $\mathrm{NAO}-$ phases (particularly in January); that is, a $-80 \%$ change (Fig. 5). On the other hand, during conditions associated with NAO- phase, the air masses are more stagnant on the centre and south of Europe, allowing the accumulation of $\mathrm{BaP}$, as shown in Figs. 4 and 5 (left column). In fact, the concentrations over the Po Valley (northern Italy), Switzerland 


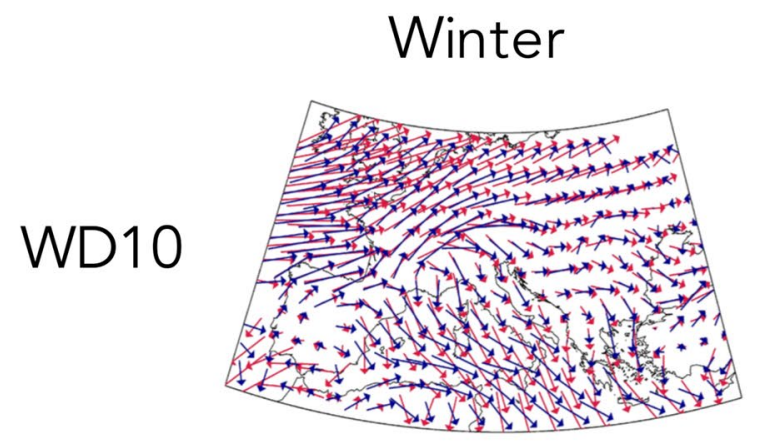

\section{Summer}

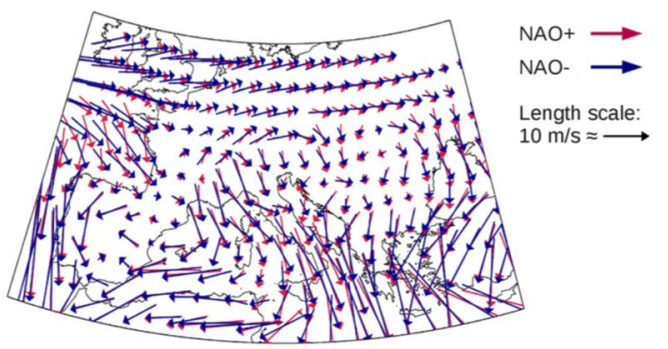

WM10
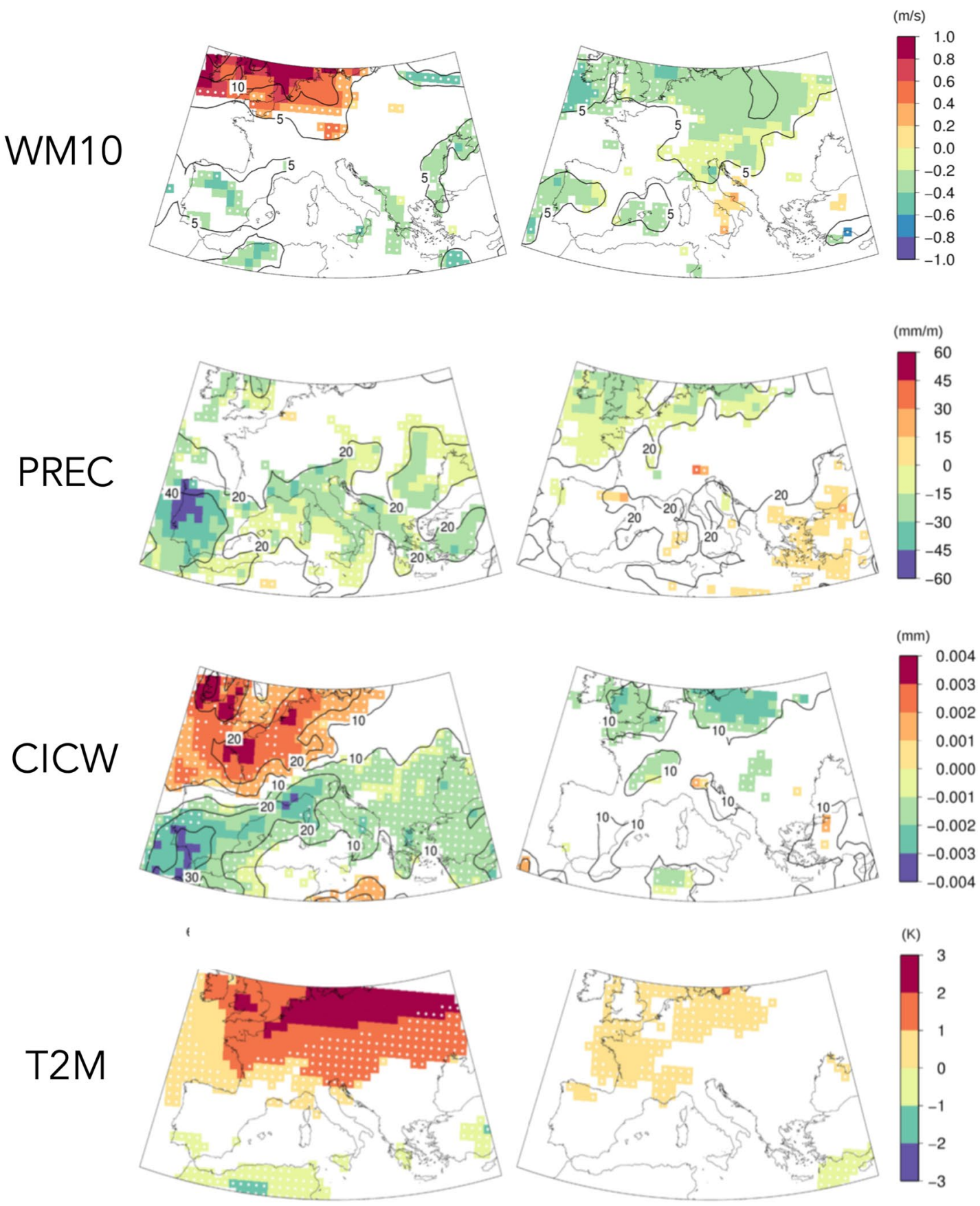
4Fig. 2 NAO impact in winter (left) and summer (right) on atmospheric conditions. (First to bottom rows) $10-\mathrm{m}$ wind direction (WD10) during NAO+ (red) and NAO- (blue) phases (arrow proportional to the wind speed); NAO+ minus NAO- for the mean $10 \mathrm{~m}$-wind module (WM10) $\left(\mathrm{m} \mathrm{s}^{-1}\right)$, precipitation (PREC) $(\mathrm{mm}$ $\left.\mathrm{month}^{-1}\right)$, column integrated cloud water (CICW) (mm) and 2-m temperature $(\mathrm{T} 2 \mathrm{M})(\mathrm{K})$. Results are only represented only if significant $(\mathrm{p}<0.1)$. Dots blur the values not representing a $\mathrm{S} / \mathrm{N}$ ratio $>1$, and contours depict differences expressed as percentage (adapted from Jerez et al. (2013b))

and Austria may change over $0.20 \mathrm{ng} \mathrm{m}^{-3}$ (changes around $100 \%$ ) in NAO+ vs. NAO- phases.

In summer, NAO- phases usually display more intense west flows in the north of Europe than NAO+ phases, with the wind module (10-m wind speed $\mathrm{NAO}+$ minus NAO-) showing differences above $0.4 \mathrm{~m} \mathrm{~s}^{-1}$ (corresponding to a $5 \%$ change) (not shown) and extending more eastwards than in winter. The scenario of stronger winds matching the NAO- phase also occurs more frequently in the southwest of the domain in the warmer months, particularly around the Iberian Peninsula (10-m wind speed NAO+ minus $\mathrm{NAO}-$ resulting in differences of $\left.-0.3 \mathrm{~m} \mathrm{~s}^{-} 1\right)$. During summer, BaP changes are similar for the entire period (increases of $0.10-0.15 \mathrm{ng} \mathrm{m}^{-3}$ during NAO+ phases vs. NAO- phases, $+60 \%$, since the $\mathrm{NAO}+$ concentration is about $0.25 \mathrm{ng} \mathrm{m}^{-3}$ and during NAO- is about $0.15 \mathrm{ng} \mathrm{m}^{-3}$ ) (Fig. 3), but displaced towards central and northern Europe as the summer advances (Belgium, the Netherlands and Poland in June-July; northeast France and the British Isles, especially in August), since the role of $\mathrm{NAO}+$ in reducing wind, precipitation and cloudiness is more noticeable there.

In line with the winter findings, the strong effect of the NAO in this area and season is indicated by the wide ranges in the $\mathrm{BaP}$ levels between both NAO phases, which can rise up to $100 \%$ (Fig. 5) especially in Belgium, the Netherlands and the British Isles. In the latter, however, results have to be taken carefully: BaP concentrations are below $0.05 \mathrm{ng} \mathrm{m}^{-3}$ during both NAO+ and NAO- phases (Fig. 3). In northcentral Europe, the corresponding increments associated with $\mathrm{NAO}+$ phase can reach or in some cases even surpass $0.20 \mathrm{ng} \mathrm{m}^{-3}$ in absolute value during August (Fig. 4).

Although wind is a key parameter for atmospheric presence of BaP, other factors can also be decisive on the incidence of this kind of mostly-particulate airborne pollutants, like precipitation and temperature. Rainfall promotes the wet deposition of particulate-bound compounds including PAHs (Birgü et al. 2011), and consequently, the decrease of their air concentrations. The NAO+ minus NAO- variances in precipitation are higher in winter and negative overall (Jerez et al. 2013a), affecting mainly the south of the domain and ranging from 40 to $20 \%$ from west to east, respectively.
In summer, the differences only reach $20 \%$ over most of Europe, being negative in the North and positive (and weaker) in the South. Observing Fig. 5, the matches are not evident with the differences in $\mathrm{BaP}$ concentrations. Although stronger in winter as well, they are not always negative (particularly in southern Europe) and in the summer months the negative trends in the North are also not seen.

This suggests that the influence of dry deposition may not be the most decisive for $\mathrm{BaP}$ atmospheric levels. Instead, temperature has a strong influence on the emission patterns, transport behaviour, and environmental distribution of SVOCs. For example, high temperatures promote the revolatilisation of chemicals like PAHs from soil and the ocean into the atmosphere and enhance the gas-phase distribution, contributing to the decrease of the respective half-lives (Delgado-Saborit et al. 2013). When applying the GEOS-Chem model to atmospheric PAHs, Friedman and Selin (Friedman and Selin 2012) identified the inclusion of secondary sources like revolatilization from soils (and to a much lesser extent from water bodies) as a priority for future modelling strategies. To address this issue, Zhang et al. (2017) mentioned that multi-year simulations and multi-compartment modules are mandatory, along with a dry-deposition parameterization (Zhang et al. 2015). In any case, the authors refer that this phenomenon is prone to affect essentially the more volatile 3 and 4-aromatic ring PAHs and not so much the modelled concentrations of 5-ringed $\mathrm{BaP}$.

In turn, lower temperatures prompt the population to increase the use of PAH-emitting sources like traffic or building heating and for this reason are commonly linked with a higher atmospheric presence of PAHs (Morville et al. 2011). Nonetheless, this fact is not included in this contribution since road emissions in this study are not sensitive to temperature and the influence of temperature on BaP levels is established through changes in transport patterns and photochemistry instead, and indirectly through emissions temporal profiles.

The impact of the NAO on the mean 2-m air temperature is also reported by Jerez et al. (2013a), and the authors refer that the most significant signal is the positive $\mathrm{NAO}+$ minus NAO- differences in winter (reaching $3 \mathrm{~K}$ ) over the north of Europe, together with lower negative (positive) variations (only up to $1 \mathrm{~K}$ ) found in some southern (northern) territories in the colder (warmer) months. In this case, the $\mathrm{BaP}$ concentration differences (Fig. 4) seem to be inversely correlated with those of the temperature (especially in winter), which is in line with the aforementioned tendency to have higher (lower) PAHs incidence with lower (higher) temperatures (Garrido et al. 2014).

As for other types of airborne particulate pollutants (Jerez et al. 2013a), the variation of several climatic indicators such 

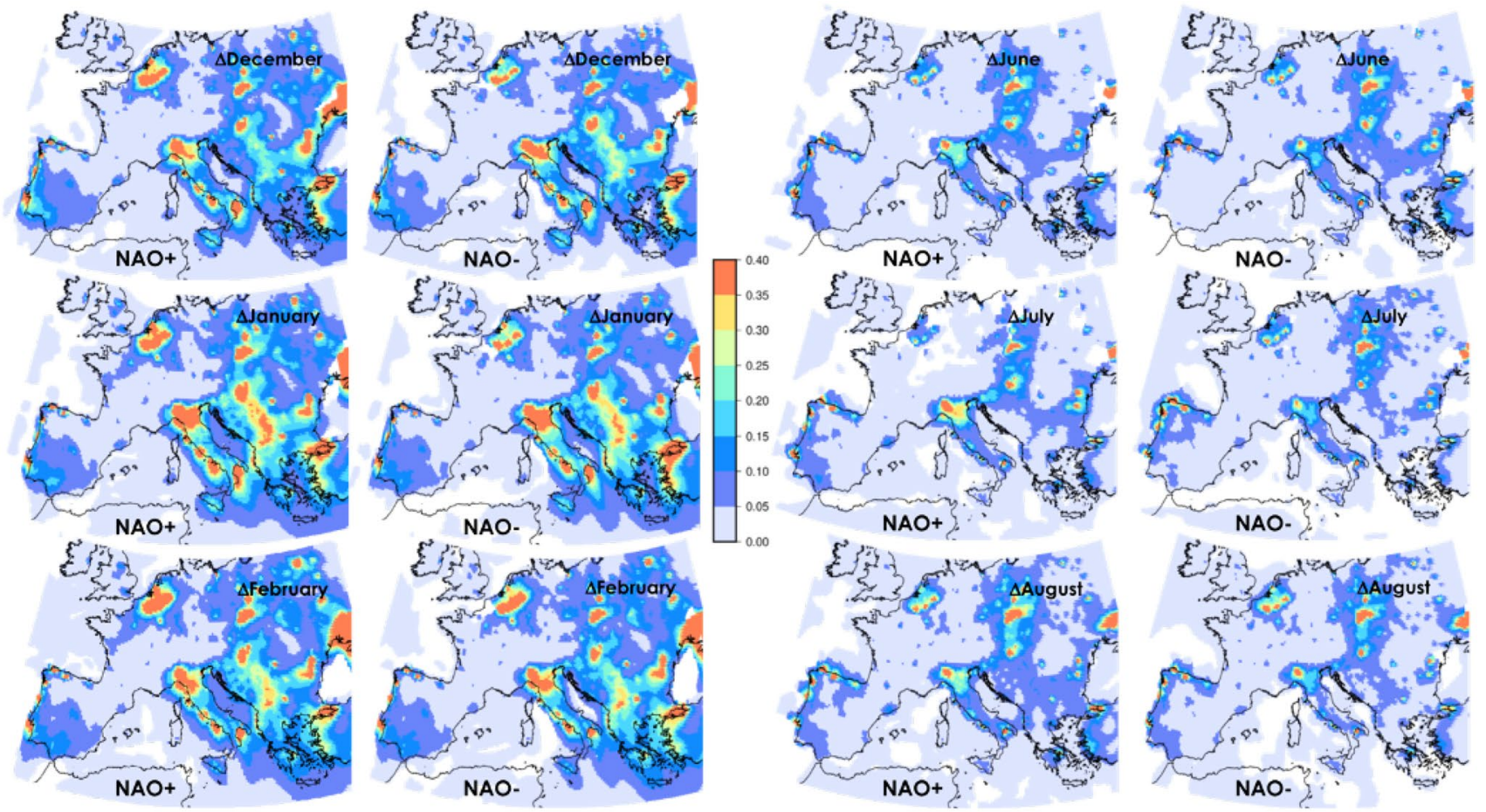

Fig. 3 Absolute ground-level concentrations $\left(\mathrm{ng} \mathrm{m}^{-3}\right.$ ) of $\mathrm{BaP}$ averaged during periods with $\mathrm{NAO}+$ and $\mathrm{NAO}-$ phases for winter (left) and summer (right) months; 1971-2000

as temperature (mainly in the north), the distribution of rain or the wind patterns associated with shifts in the NAO parameter are also closely related to the influence of NAO on BaP air levels. A summary of the variables involved can be found in Fig. 6 .

\section{Conclusions}

The effect of climate phenomena like the North Atlantic Oscillation (NAO) is evident not only on meteorological parameters like temperature, wind or precipitation, but also on the distribution and transport of macropollutants (substances that comprise $90-95 \%$ of the mass fraction of environmental pollutant release) and micropollutants (substances with a small share, both with an organic-PAHs, pesticides, organohalogen compounds, etc.—or inorganic-metalloids, heavy metals and radionuclides-origin) (Konstantinova et al. 2020). This entails impacts from the local to the global scale which are challenging to assess.

This contribution sheds some light on the process-understanding related to the atmospheric concentration of PAHs, one of the most studied organic micropollutant families. In fact, when the concentrations of $\mathrm{BaP}$ (the most commonly used $\mathrm{PAH}$ congener) during $\mathrm{NAO}+$ minus $\mathrm{NAO}-$ phases are estimated over Europe, strongly marked effects can be perceived temporally and spatially, namely yielding differences between seasons and north and south, respectively. While the Mediterranean basin displays a greater incidence of $\mathrm{BaP}$ in colder months during the NAO+ phase, summer brings the same signals up north. As a consequence, the mean $\mathrm{BaP}$ concentrations can vary $100 \%$ or in some cases even more, being of the same order of magnitude as the variations found for different daily meteorological conditions. Lighter evidences of opposite trends can also be detected, such as the NAO- phase inducing an increase in BaP levels are observed in northern locations in winter and southern ones in the warmer months. Even taking into consideration that our approach focuses on local-governing processes of air pollution, these results agree with those of Christoudias et al. (2012) in the sense that a stronger Azores High in the NAO+ phase increases the north-to-south transport in Europe and therefore higher $\mathrm{BaP}$ incidence.

Apart from enhancing the state-of-the-art on key correlations between climate and air quality, the current study sets the foundations towards (1) improving the predictability of BaP pollution episodes (a considerable body of work is under way to improve the accuracy in the prediction of large-scale circulation modes (e.g. Brands et al. (2012)), and (2) understanding NAO future projections on the long-term (still uncertain) regarding air quality. In addition, the present contribution highlights that meteorological conditions under different phases of the NAO can increase the ground levels of $\mathrm{BaP}$ independently of the emissions. Therefore, 

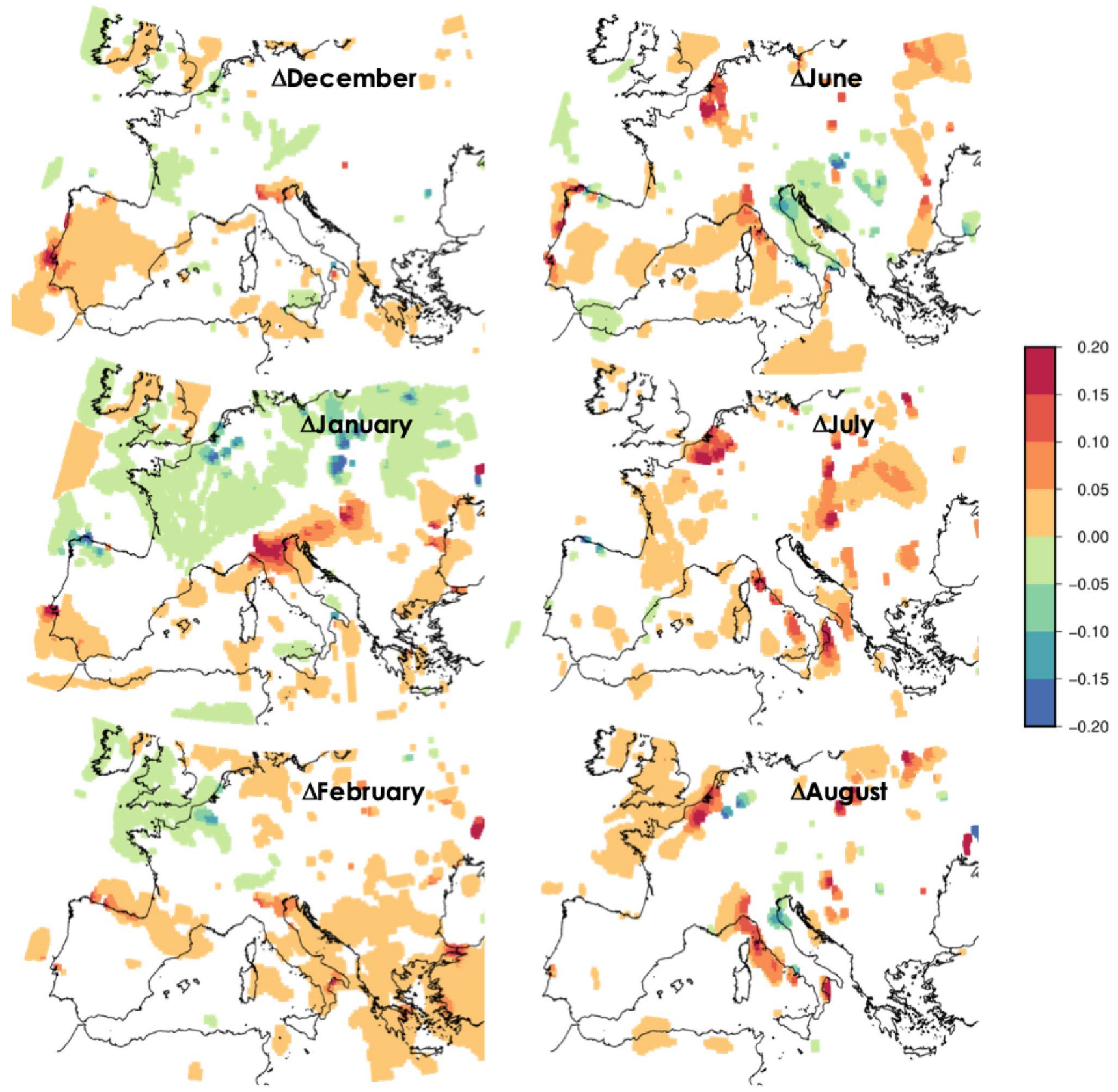

Fig. 4 Absolute ground-level differences ( $\mathrm{ng} \mathrm{m}^{-3}$ ) in $\mathrm{BaP}$ concentrations between NAO+ and NAO- phases for winter (left) and summer (right) months; 1971-2000. Results are only shown where statistically significant $(\mathrm{p}<0.1)$

from a regulatory point of view, it should be born in mind that efforts devoted to reduce PAHs emissions in order to improve air quality can be hampered by the climate penalty associated to the enhanced levels caused by the natural climatic variability.
New chemicals are being produced and released into the environment and their hazardous potential and worldwide distribution need to be assessed as fast as possible. Modelling approaches need detailed information on the emission patterns and substantial field-based data prior to their development. In this sense, field sampling becomes 

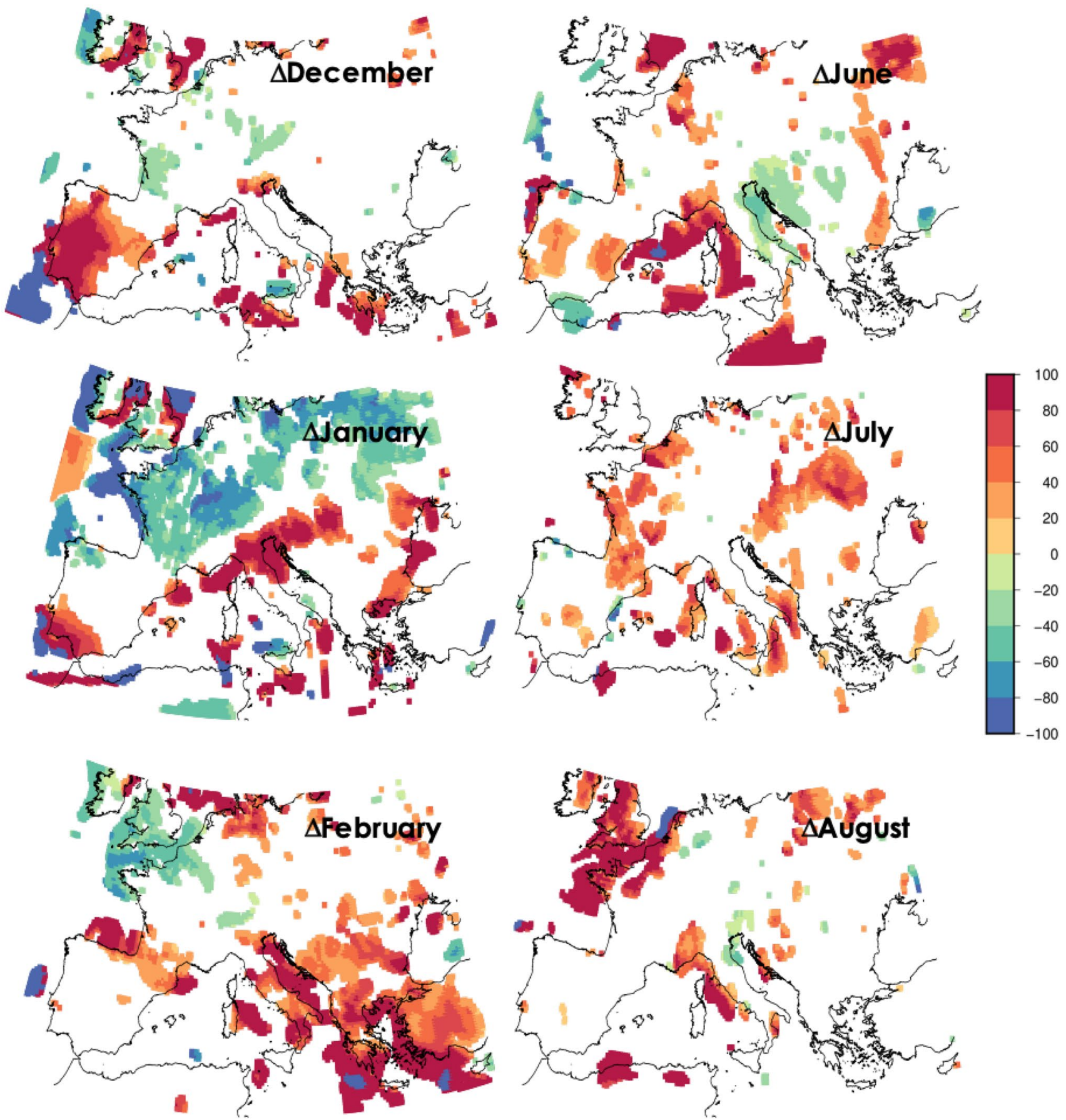

Fig. 5 Differences (\%) in ground-level BaP concentrations between NAO+ and NAO-phases for winter (left) and summer (right) months; 1971-2000. Results are only shown where statistically significant $(p<0.1)$

an essential tool to determine the occurrence of hazardous compounds in the environment. Active and especially passive air sampling can provide information on the levels of many pollutants at different locations including remote areas, with a relative low-cost and easy maintenance setup (Domínguez-Morueco et al. 2019). Nevertheless, to help the transformation of these valuable datasets onto a complete understanding of spatial, temporal and chemical 


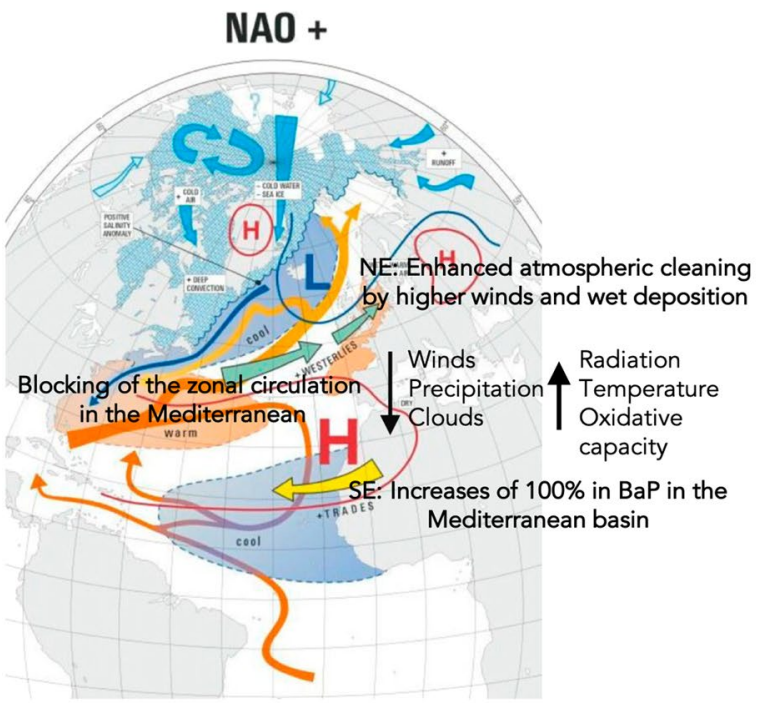

NAO -

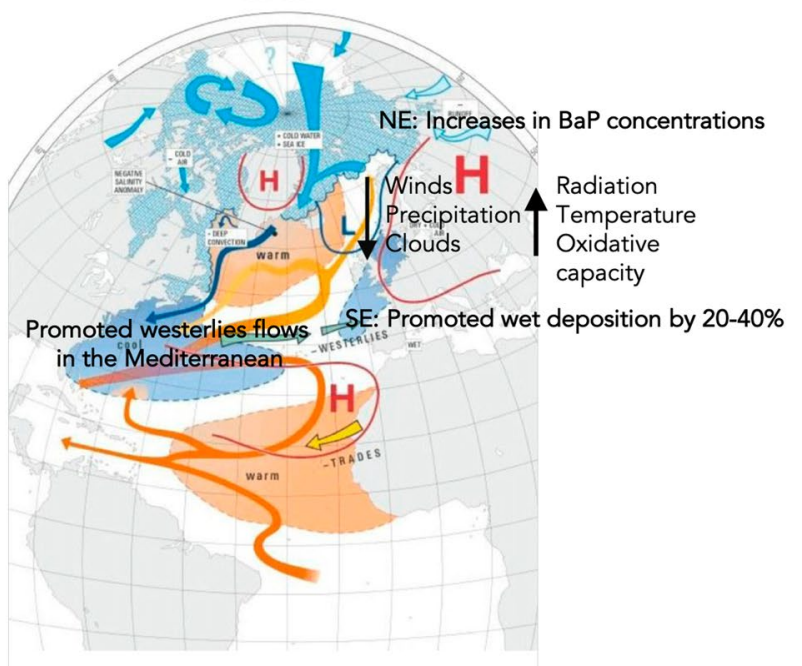

Fig. 6 Summary of the processes involved in the NAO impacts on the concentration of $\mathrm{BaP}$ during (top) NAO+ phase and (bottom) NAOphase (base image adapted from Wanner et al. (2001))

transport patterns it is essential to combine the field observations with modelling tools (Ratola and Jiménez-Guerrero 2016). If even for $\mathrm{BaP}$, which has been studied for decades, we have important uncertainties, there is a need to reduce the time it takes to have reliable simulations for both legacy and emerging threats and the influence phenomena like NAO have on their presence and fate.

Supplementary Information The online version contains supplementary material available at https://doi.org/10.1007/s00382-021-05766-0.

Author contributions Both authors contributed equally to the findings in this contribution.
Funding This work was funded by the European Union Seventh Framework Programme-Marie Curie COFUND (FP7/2007-2013) under UMU Incoming Mobility Programme ACTion (U-IMPACT) Grant Agreement 267143; the Spanish Ministry of Economy and Competitiveness/Agencia Estatal de Investigación and the European Regional Development Fund (ERDF/FEDER) (ACEX-CGL2017-87921-R). N.R. thanks (i) Project UID/EQU/00511/2019—Laboratory for Process Engineering, Environment, Biotechnology and Energy_LEPABE funded by national funds through FCT/MCTES (PIDDAC); (ii) Portuguese Foundation for Science and Technology (FCT) for the financial support of his work contract through the Scientific Employment Stimulus-Institutional Call-[CEECINST/00049/2018]; and (iii) the "Programa Jiménez de la Espada" (ref. 19641/IV/14) from Fundación Séneca-Science and Technology Agency in the Region of Murcia.

Availability of data and material The data that support the findings of this study are available from the corresponding author, P.J.-G., upon reasonable request (pedro.jimenezguerrero@um.es).

\section{Declarations}

Conflict of interest The authors declare that they have no conflict of interest.

Open Access This article is licensed under a Creative Commons Attribution 4.0 International License, which permits use, sharing, adaptation, distribution and reproduction in any medium or format, as long as you give appropriate credit to the original author(s) and the source, provide a link to the Creative Commons licence, and indicate if changes were made. The images or other third party material in this article are included in the article's Creative Commons licence, unless indicated otherwise in a credit line to the material. If material is not included in the article's Creative Commons licence and your intended use is not permitted by statutory regulation or exceeds the permitted use, you will need to obtain permission directly from the copyright holder. To view a copy of this licence, visit http://creativecommons.org/licenses/by/4.0/.

\section{References}

Alizadeh-Choobari O, Adibi P (2019) Impacts of large-scale teleconnections on climate variability over southwest Asia. Dyn Atmos Oceans 86:41-51. https://doi.org/10.1016/j.dynatmoce. 2019.02.001

Almendra R, Santana P, Vasconcelos J, Silva G, Gonçalves F, Ambrizzi T (2017) The influence of the winter North Atlantic Oscillation index on hospital admissions through diseases of the circulatory system in Lisbon, Portugal. Int J Biometeorol 61(2):325-333. https://doi.org/10.1007/s00484-016-1214-z

ATSDR (1995) Toxicological profile for polycyclic aromatic hydrocarbons (pahs). US Agency for Toxic Substances and Disease Registry, Atlanta, GA

Bacer S, Christoudias T, Pozzer A (2016) Projection of North Atlantic Oscillation and its effect on tracer transport. Atmos Chem Phys 16(24):15581-15592. https://doi.org/10.5194/ acp-16-15581-2016

Bidleman TF (1988) Atmospheric processes. Environ Sci Technol 22(4):361-367. https://doi.org/10.1021/es00169a002

Birgül A, Tasdemir Y, Cindoruk SS (2011) Atmospheric wet and dry deposition of polycyclic aromatic hydrocarbons (pahs) determined using a modified sampler. Atmos Res 101(1):341-353. https://doi.org/10.1016/j.atmosres.2011.03.012 
Bladé I, Liebmann B, Fortuny D, van Oldenborgh GJ (2012) Observed and simulated impacts of the summer NAO in Europe: implications for projected drying in the Mediterranean region. Clim Dyn 39(3):709-727. https://doi.org/10.1007/s00382-011-1195-x

Brands S, Manzanas R, Gutiérrez JM, Cohen J (2012) Seasonal Predictability of Wintertime Precipitation in Europe Using the Snow Advance Index. J Clim 25(12):4023-4028. https://doi.org/ 10.1175/JCLI-D-12-00083.1

Callén MS, de la Cruz MT, López JM, Murillo R, Navarro MV, Mastral AM (2008) Long-Range Atmospheric Transport and Local Pollution Sources on PAH Concentrations in a South European Urban Area. Fulfilling of the European Directive. Water Air Soil Pollut 190(1):271-285. https://doi.org/10.1007/s11270-007-9599-2

Camarero L, Bacardit M, de Diego A, Arana G (2017) Decadal trends in atmospheric deposition in a high elevation station: Effects of climate and pollution on the long-range flux of metals and trace elements over sw europe. Atmos Environ 167:542-552. https:// doi.org/10.1016/j.atmosenv.2017.08.049

Christoudias T, Pozzer A, Lelieveld J (2012) Influence of the North Atlantic Oscillation on air pollution transport. Atmos Chem Phys 12(2):869-877. https://doi.org/10.5194/acp-12-869-2012

Comas-Bru L, Hernández A (2018) Reconciling north atlantic climate modes: revised monthly indices for the east atlantic and the scandinavian patterns beyond the 20th century. Earth Syst Sci Data 10(4):2329-2344. https://doi.org/10.5194/essd-10-2329-2018

Dat ND, Chang MB (2017) Review on characteristics of pahs in atmosphere, anthropogenic sources and control technologies. Sci Total Environ 609:682-693. https://doi.org/10.1016/j.scito tenv.2017.07.204

Dayan U (2011) Impacts of the NAO on Atmospheric Pollution in the Mediterranean Basin, Springer Netherlands, Dordrecht, pp 171-181. https://doi.org/10.1007/978-94-007-1372-7_12

Dayan U, Ricaud P, Zbinden R, Dulac F (2017) Atmospheric pollution over the eastern Mediterranean during summer - a review. Atmos Chem Phys 17(21):13233-13263. https://doi.org/10. 5194/acp-17-13233-2017

Delgado-Saborit JM, Alam MS, Godri Pollitt KJ, Stark C, Harrison RM (2013) Analysis of atmospheric concentrations of quinones and polycyclic aromatic hydrocarbons in vapour and particulate phases. Atmos Environ 77:974-982. https://doi.org/10.1016/j. atmosenv.2013.05.080

Domínguez-Morueco N, Ratola N, Sierra J, Nadal M, Jiménez-Guerrero $\mathrm{P}$ (2019) Combining monitoring and modelling approaches for bap characterization over a petrochemical area. Sci Total Environ 658:424-438. https://doi.org/10.1016/j.scitotenv.2018.12.202

Eckhardt S, Stohl A, Beirle S, Spichtinger N, James P, Forster C, Junker C, Wagner T, Platt U, Jennings SG (2003) The North Atlantic Oscillation controls air pollution transport to the Arctic. Atmospheric Chemistry and Physics. https://doi.org/10.5194/ acp-3-1769-2003

EEA (2019) Air Quality in Europe - 2019. Tech. Rep. EEA Report No. 10/2019, European Environment Agency, Copenhagen, Denmark

EU (2004) Directive 2004/107/EC of the European Parliament and of the Council of 15 December 2004 Relating to Arsenic, Cadmium, Mercury, Nickel and Polycyclic Aromatic Hydrocarbons in Ambient Air. Tech. Rep. OJ L 23, 26.1.2005, European Union

Friedman CL, Selin NE (2012) Long-range atmospheric transport of polycyclic aromatic hydrocarbons: A global 3-D model analysis including evaluation of arctic sources. Environ Sci Technol 46(17):9501-9510. https://doi.org/10.1021/es301904d

Garrido A, Jiménez-Guerrero P, Ratola N (2014) Levels, trends and health concerns of atmospheric PAHs in Europe. Atmos Environ 99:474-484. https://doi.org/10.1016/j.atmosenv.2014.10.011

Grams CM, Beerli R, Pfenninger S, Staffell I, Wernli H (2017) Balancing Europe's wind-power output through spatial deployment informed by weather regimes. Nat Clim Change 7(8):557-562. https://doi.org/10.1038/nclimate3338

Greatbatch RJ (2000) The North Atlantic oscillation. Stoch Env Res Risk Assess 14(4):213-242. https://doi.org/10.1007/s004770000 047

Guerreiro C, Horálek J, de Leeuw F, Couvidat F (2016) Benzo(a)pyrene in Europe: Ambient air concentrations, population exposure and health effects. Environ Pollut 214:657-667. https://doi.org/ 10.1016/j.envpol.2016.04.081

Hung H, Blanchard P, Halsall C, Bidleman T, Stern G, Fellin P, Muir D, Barrie L, Jantunen L, Helm P, Ma J, Konoplev A (2005) Temporal and spatial variabilities of atmospheric polychlorinated biphenyls (pcbs), organochlorine (oc) pesticides and polycyclic aromatic hydrocarbons (pahs) in the canadian arctic: Results from a decade of monitoring. Science of The Total Environment 342(1): 119 - 144, https://doi.org/10.1016/j.scitotenv.2004.12.058, sources, Occurrence, Trends and Pathways of Contaminants in the Arctic

Hurrell JW (1995) Decadal trends in the North Atlantic oscillation: regional temperatures and precipitation. Science 269(5224):676679. https://doi.org/10.1126/science.269.5224.676

Hurrell J, Kushnir Y, Ottersen G, Visbeck M (2003) An overview of the North Atlantic Oscillation, American Geophysical Union, Washington, pp 1-35. https://doi.org/10.1029/134GM01

Izquierdo R, Alarcón M, Aguillaume L, Àvila A (2014) Effects of teleconnection patterns on the atmospheric routes, precipitation and deposition amounts in the north-eastern iberian peninsula. Atmos Environ 89:482-490. https://doi.org/10.1016/j.atmosenv. 2014.02.057

Jerez S, Jiménez-Guerrero P, Montávez JP, Trigo RM (2013a) Impact of the North Atlantic Oscillation on European aerosol ground levels through local processes: a seasonal model-based assessment using fixed anthropogenic emissions. Atmos Chem Phys 13(22):11195-11207. https://doi.org/10.5194/acp-13-11195-2013

Jerez S, Trigo RM, Vicente-Serrano SM, Pozo-Vázquez D, LorentePlazas R, Lorenzo-Lacruz J, Santos-Alamillos F, Montávez JP (2013b) The Impact of the North Atlantic oscillation on renewable energy resources in Southwestern Europe. J Appl Meteorol Climatol 52(10):2204-2225. https://doi.org/10.1175/ JAMC-D-12-0257.1

Jiménez-Guerrero P, Montávez JP, Gómez-Navarro JJ, Jerez S, Lorente-Plazas R (2012) Impacts of climate change on ground level gas-phase pollutants and aerosols in the iberian peninsula for the late xxi century. Atmos Environ 55:483-495. https://doi.org/10. 1016/j.atmosenv.2012.02.048

Keyte IJ, Harrison RM, Lammel G (2013) Chemical reactivity and long-range transport potential of polycyclic aromatic hydrocarbons-a review. Chem Soc Rev 42(24):9333-9391. https://doi.org/ 10.1039/C3CS60147A

Konstantinova E, Minkina T, Sushkova S, Antonenko E, Konstantinov A (2020) Levels, sources, and toxicity assessment of polycyclic aromatic hydrocarbons in urban topsoils of an intensively developing Western Siberian city. Environ Geochem Health 42(1):325341. https://doi.org/10.1007/s10653-019-00357-9

Kumar P, Min SK, Weller E, Lee H, Wang XL (2016) Influence of climate variability on extreme ocean surface wave heights assessed from ERA-Interim and ERA-20C. J Clim 29(11):4031-4046. https://doi.org/10.1175/JCLI-D-15-0580.1

Lammel G, Sehili AM, Bond TC, Feichter J, Grassl H (2009) Gas/ particle partitioning and global distribution of polycyclic aromatic hydrocarbons - a modelling approach. Chemosphere 76(1):98106. https://doi.org/10.1016/j.chemosphere.2009.02.017

Lammel G, Dvorská A, Klánová J, Kohoutek J, Kukucka P, Prokes R, Sehili AM (2015) Long-range atmospheric transport of polycyclic aromatic hydrocarbons is worldwide problem-results from 
measurements at remote sites and modelling. Acta Chim Slov 62(3):729-735. https://doi.org/10.17344/acsi.2015.1387

Lhotka R, Pokorná P, Zíková N (2019) Long-term trends in PAH concentrations and sources at rural background site in central Europe. Atmosphere 10(11):687. https://doi.org/10.3390/atmos10110687

Li Q, Jacob DJ, Bey I, Palmer PI, Duncan BN, Field BD, Martin RV, Fiore AM, Yantosca RM, Parrish DD, Simmonds PG, Oltmans SJ (2002) Transatlantic transport of pollution and its effects on surface ozone in Europe and North America. J Geophys Res Atmos 107(D13):4-21. https://doi.org/10.1029/2001JD001422

Linares C, Díaz J, Negev M, Martínez GS, Debono R, Paz S (2020) Impacts of climate change on the public health of the mediterranean basin population - current situation, projections, preparedness and adaptation. Environ Res 182:109107. https://doi.org/10. 1016/j.envres.2019.109107

Ma J, Cao Z, Hung H (2004a) North Atlantic Oscillation signatures in the atmospheric concentrations of persistent organic pollutants: An analysis using Integrated Atmospheric Deposition NetworkGreat Lakes monitoring data. Journal of Geophysical Research D: Atmospheres https://doi.org/10.1029/2003JD004435

Ma J, Hung H, Blanchard P (2004b) How do climate fluctuations affect persistent organic pollutant distribution in North America? Evidence from a decade of air monitoring. Environ Sci Technol 38(9):2538-2543. https://doi.org/10.1021/es0349610

MacLeod M, Riley WJ, Mckone TE (2005) Assessing the influence of climate variability on atmospheric concentrations of polychlorinated biphenyls using a global-scale mass balance model (BETRGlobal). Environ Sci Technol 39(17):6749-6756. https://doi.org/ 10.1021/es048426r

Meleux F, Solmon F, Giorgi F (2007) Increase in summer European ozone amounts due to climate change. Atmos Environ 41(35):7577-7587. https://doi.org/10.1016/j.atmosenv.2007.05. 048

Morville S, Delhomme O, Millet M (2011) Seasonal and diurnal variations of atmospheric PAH concentrations between rural, suburban and urban areas. Atmosp Pollut Res 2(3):366-373. https://doi.org/ 10.5094/APR.2011.041

Moulin C, Lambert CE, Dulac F, Dayan U (1997) Control of atmospheric export of dust from North Africa by the North Atlantic Oscillation. Nature 387(6634):691-694. https://doi.org/10.1038/ 42679

Mu Q, Shiraiwa M, Octaviani M, Ma N, Ding A, Su H, Lammel G, Pöschl U, Cheng Y (2018) Temperature effect on phase state and reactivity controls atmospheric multiphase chemistry and transport of PAHs. Sci Adv https://doi.org/10.1126/sciadv.aap7314

Nisbet IC, LaGoy PK (1992) Toxic equivalency factors (tefs) for polycyclic aromatic hydrocarbons (pahs). Regul Toxicol Pharmacol 16(3):290-300. https://doi.org/10.1016/0273-2300(92)90009-X

Octaviani M, Stemmler I, Lammel G, Graf HF (2015) Atmospheric transport of persistent organic pollutants to and from the arctic under present-day and future climate. Environ Sci Technol 49(6):3593-3602. https://doi.org/10.1021/es505636g

Pey J, Querol X, Alastuey A, Forastiere F, Stafoggia M (2013) African dust outbreaks over the Mediterranean Basin during 2001-2011: PM10 concentrations, phenomenology and trends, and its relation with synoptic and mesoscale meteorology. Atmos Chem Phys 13(3):1395-1410. https://doi.org/10.5194/acp-13-1395-2013

Poli P, Hersbach H, Dee DP, Berrisford P, Simmons AJ, Vitart F, Laloyaux P, Tan DGH, Peubey C, Thépaut JN, Trémolet Y, Hólm EV, Bonavita M, Isaksen L, Fisher M (2016) ERA-20C: an atmospheric reanalysis of the twentieth century. J Clim 29(11):40834097. https://doi.org/10.1175/JCLI-D-15-0556.1

Ratola N, Jiménez-Guerrero P (2015) Combined field/modelling approaches to represent the air-vegetation distribution of benzo[a] pyrene using different vegetation species. Atmos Environ 106:3442. https://doi.org/10.1016/j.atmosenv.2015.01.063
Ratola N, Jiménez-Guerrero P (2016) Can biomonitors effectively detect airborne benzo[a]pyrene? An evaluation approach using modelling. Atmos Chem Phys 16(7):4271-4282. https://doi.org/ 10.5194/acp-16-4271-2016

Ratola N, Jiménez-Guerrero P (2017) Modelling benzo[a]pyrene in air and vegetation for different land uses and assessment of increased health risk in the Iberian Peninsula. Environ Sci Pollut Res 24(13):11901-11910. https://doi.org/10.1007/s11356-015-5394-6

Ravindra K, Sokhi R, Van Grieken R (2008) Atmospheric polycyclic aromatic hydrocarbons: source attribution, emission factors and regulation. Atmos Environ 42(13):2895-2921. https://doi.org/10. 1016/j.atmosenv.2007.12.010

Schreiberová M, Vlasáková L, Vlček O, Šmejdířová J, Horálek J, Bieser J (2020) Benzo[a]pyrene in the ambient air in the Czech Republic: emission sources, current and long-term monitoring analysis and human exposure. Atmosphere 11(9):955. https://doi. org/10.3390/atmos11090955

Shrivastava M, Lou S, Zelenyuk A, Easter RC, Corley RA, Thrall BD, Rasch PJ, Fast JD, Massey Simonich SL, Shen H, Tao S (2017) Global long-range transport and lung cancer risk from polycyclic aromatic hydrocarbons shielded by coatings of organic aerosol. Proc Natl Acad Sci 114(6):1246-1251. https://doi.org/10.1073/ pnas. 1618475114

Snedecor G, Cochran W (1989) Statistical methods, 8th edn. Iowa State University Press, Iowa

Stenseth NC, Mysterud A, Ottersen G, Hurrell JW, Chan KS, Lima M (2002) Ecological effects of climate fluctuations. Science 297(5585):1292-1296. https://doi.org/10.1126/science.1071281

Tørseth K, Aas W, Breivik K, Fjæraa AM, Fiebig M, Hjellbrekke AG, Lund Myhre C, Solberg S, Yttri KE (2012) Introduction to the European monitoring and evaluation Programme (EMEP) and observed atmospheric composition change during 1972-2009. Atmos Chem Phys 12(12):5447-5481. https://doi.org/10.5194/ acp-12-5447-2012

Trigo IF (2006) Climatology and interannual variability of storm-tracks in the Euro-Atlantic sector: a comparison between ERA-40 and NCEP/NCAR reanalyses. Clim Dyn 26(2):127-143. https://doi. org/10.1007/s00382-005-0065-9

Trigo R, Osborn T, Corte-Real J (2002) The North Atlantic Oscillation influence on Europe: climate impacts and associated physical mechanisms. Clim Res 20:9-17. https://doi.org/10.3354/cr020009

Turco M, Jerez S, Augusto S, Tarín-Carrasco P, Ratola N, JiménezGuerrero P, Trigo RM (2019) Climate drivers of the 2017 devastating fires in Portugal. Sci Rep 9(1):13886. https://doi.org/10. 1038/s41598-019-50281-2

Viana M, de Leeuw F, Bartonova A, Castell N, Ozturk E, González Ortiz A (2020) Air quality mitigation in European cities: status and challenges ahead. Environ Int 143:105907. https://doi.org/10. 1016/j.envint.2020.105907

Wang X, Gong P, Zhang Q, Yao T (2010) Impact of climate fluctuations on deposition of ddt and hexachlorocyclohexane in mountain glaciers: Evidence from ice core records. Environ Pollut 158(2):375-380. https://doi.org/10.1016/j.envpol.2009.09.006

Wanner H, Brönnimann S, Casty C, Gyalistras D, Luterbacher J, Schmutz C, Stephenson DB, Xoplaki E (2001) North Atlantic oscillation-concepts and studies. Surv Geophys 22(4):321-381. https://doi.org/10.1023/A:1014217317898

Zhang L, Cheng I, Wu Z, Harner T, Schuster J, Charland JP, Muir D, Parnis JM (2015) Dry deposition of polycyclic aromatic compounds to various land covers in the athabasca oil sands region. $\mathbf{J}$ Adv Model Earth Syst 7(3):1339-1350. https://doi.org/10.1002/ 2015MS000473

Zhang J, Li J, Wang P, Chen G, Mendola P, Sherman S, Ying Q (2017) Estimating population exposure to ambient polycyclic aromatic hydrocarbon in the united states-part i: Model development and 
evaluation. Environ Int 99:263-274. https://doi.org/10.1016/j. envint.2016.12.002

Zhou S, Hwang BCH, Lakey PSJ, Zuend A, Abbatt JPD, Shiraiwa M (2019) Multiphase reactivity of polycyclic aromatic hydrocarbons is driven by phase separation and diffusion limitations. Proc Natl Acad Sci 116(24):11658-11663. https://doi.org/10.1073/pnas. 1902517116
Publisher's Note Springer Nature remains neutral with regard to jurisdictional claims in published maps and institutional affiliations. 